\title{
Internacionalização de Empresas Participantes de Clusters: Condicionantes e práticas relacionais
}

\author{
Sergio Bulgacov- Escola de Administração de Empresas de São Paulo - Fundação \\ Getúlio Vargas ${ }^{1}$ \\ Sieglin de Kindl Cunha- Universidade Federal do Paraná - Universidade Positivo² \\ Yara Bulgacov- Universidade Federal do Paraná - Universidade Positivo ${ }^{3}$ \\ João Carlos Cunha- Universidade Positivo - Universidade São Paulo ${ }^{4}$ \\ Zandra Balbinot- Universidade Federal do Paraná
}

\begin{abstract}
Resumo
Este trabalho tem como objetivo identificar os condicionantes endógenos e exógenos dos processos relacionais para a internacionalização de empresas participantes de cinco Clusters do Paraná, Brasil. O referencial teórico se concentra nas práticas de redes interorganizacionais e no processo de internacionalização de empresas. A pesquisa tem como referência a metodologia do estudo de casos múltiplos, com abordagem qualitativa e finalidade descritiva. Os dados foram coletados por meio de trinta e nove entrevistas, por observação não participante e por análises documentais com a utilização de relatórios, atas de reuniões, atos de constituição e normatizações existentes nas governanças de cada um dos Clusters. Quanto aos resultados obtidos, identifica-se que os efeitos dos condicionantes endógenos e exógenos são simultâneos e correlacionados, dificultando o estabelecimento da exata influência de um fator isolado sobre os resultados das ações coletivas. Constata-se também que diferentes contextos e configurações das relações determinam a forma, os condicionantes e a influência específica no processo de internacionalização pretendido. Os resultados das análises das relações interorganizacionais permitiram identificar alguns subsídios qualitativos para compreensão dos fenômenos estudados que devem ser considerados como sugestões de estudos futuros.
\end{abstract}

Palavras chaves: redes interorganizacionais, clusters, internacionalização.

\section{Resumen}

Este estudio tiene como objetivo identificar los determinantes endógenos y exógenos de los procesos relacionales para la internacionalización de las empresas participantes en cinco Clusters de Paraná - Brasil. El marco teórico se centra en la práctica de redes organizacionales y en el proceso de internacionalización de las empresas. La encuesta tiene en referencia a la metodología de estudio de casos múltiples con una finalidad cualitativa y descriptiva. Los datos fueron recolectados a través de treinta y nueve

\footnotetext{
${ }^{1}$ s.bulgacov@gmail.com

2 skcunha21@gmail.com

3 ybulgacov@gmail.com

4 jccunha@ufpr.br
} 
entrevistas, observación no participante y análisis documental con el uso de informes, actas de reuniones, actos de constitución y normas de gobierno en cada cluster. Los resultados obtenidos identifican que los efectos de las restricciones endógenas y exógenas son simultáneos y correlacionados, por lo que es difícil establecer la influencia exacta de un factor sobre el resultado de acciones colectivas. Se dará cuenta de que los contextos diferentes y la configuración de la forma de la relación, las condiciones específicas influencia el proceso de internacionalización. Los resultados del análisis de relaciones inter-organizacionales fornecen algunos subsidios para la comprensión cualitativa de los fenómenos que deben ser considerados como sugerencias para futuros estudios.

Palavras claves: redes inter-organizacionales, clusters, internacionalización.

\begin{abstract}
This study aims to identify the endogenous and exogenous determinants of relational processes for the internationalization of business participants from five local clusters of Paraná - Brazil. The theoretical framework focuses on the practice of inter-networks and the internationalization process of firms. The poll has a reference to the methodology of multiple case study with a qualitative and descriptive purpose. Data were collected through thirty-nine interviews, non participant observation and documentary analysis with the use of reports, minutes of meetings, acts of constitution and governance of existing rules in each of the ALPs. The results obtained identified that the effects of endogenous and exogenous constraints are simultaneous and correlated, making it difficult to establish the exact influence of a single factor on the outcome of collective actions. Also that different contexts and settings determine the form of relations, constraints and the specific influence in the internationalization process desired. The results of analysis of inter-organizational pinpointed some subsidies for qualitative understanding of the phenomena that should be considered as suggestions for future studies.
\end{abstract}

Keywords: inter-networks, clusters, internationalization

\title{
Introdução
}

$\mathrm{Na}$ ótica da dependência de recursos, os estudos sobre os clusters que formam redes relacionais e parcerias interorganizacionais sugerem que esses arranjos se constituem em alternativa de superação das dificuldades para as pequenas e médias empresas. Isso ocorre pelo delineamento de modelos de negócios competitivos por meio da viabilidade coletiva da formação de novos conhecimentos. Schermerhorn Jr. (1975) considera que as empresas se relacionam cooperativamente pelas possibilidades de ampliar as suas escolhas estratégicas. E, para Balestro e Mesquita (2003), na medida em que as interrelações proporcionam possibilidades efetivas em termos de aquisição de conhecimento para as estratégias de diversificação de produtos, mercados e inovação. Reforçando o espaço coletivo para a aquisição do conhecimento Cassiolato e Lastres (2003) sugerem que o sucesso das relações interorganizacionais depende da troca, formal ou informal, de experiências e de conhecimentos entre os participantes e da existência de condições para esse fim. Assim, o ambiente para se pesquisarem os condicionantes para a internacionalização tem nos clusters campo propício para a difusão de novos 
conhecimentos e consequente geração de vantagem competitiva, tendo em vista que, primeiramente, os clusters buscam prioritariamente alcançar eficiência coletiva possibilitando a inclusão de mercados que seriam inacessíveis para cada uma das empresas individualmente (UNIDO, 2001). Nesse sentido, este trabalho concentra sua atenção nas relações interorganizacionais existente em clusters enquanto espaço dos condicionantes para a constituição do processo de internacionalização de pequenas e médias empresas.

Enquanto Casarotto Filho (2005) define a rede interorganizacional como a associação potencial de todas as entidades representativas (agentes econômicos, políticos e sociais) de uma determinada região possuidora de um propósito em comum, visando ao desenvolvimento dessa região por meio da integração e de vínculos, mesmo incipientes, o trabalho de McNamara (2005) sustenta que a rede interorganizacional é um espaço relevante para o desenvolvimento de novos processos, inclusive o da internacionalização, na medida em que promove o senso comum para o compartilhamento de conhecimento entre os seus participantes.

Nesse sentido, o objetivo deste trabalho é o de identificar os condicionantes existentes para a internacionalização de pequenas e médias empresas em cinco clusters do Estado Paraná-Brasil. Para tanto, os condicionantes são divididos em três grupos: (1) práticas relacionais, (2) fatores endógenos, e (3) fatores exógenos.

Tendo os condicionantes do processo de internacionalização das empresas como elementos de análise principal, as características dos clusters, para efeito deste trabalho, se destacam para a contextualização das práticas existentes nos objetos em estudo. 0 processo de internacionalização representa um conjunto de atividades que exige conhecimentos não comumente existentes na comunidade das pequenas empresas. Requer a constante busca por informações que oriente a adequada decisão a respeito do modo de entrada, a sua adequada caracterização como oportunidade de negócio e da permanência nos novos mercados atendendo às características da atividade e dos mercados selecionados.

Enquanto pesquisas anteriores têm o seu foco direcionado principalmente para os condicionantes para a formação e a forma da rede em termos socioeconômicos, assim como o posicionamento de uma empresa dentro de uma rede (Oliver, 1990; Grandori, Soda, 1995; Gulati, Garciulo, 1999; Cunha e Cunha, 2005; Czajkowski e Cunha, 2010; Olivares, 2003; Lima, Campos Filho, 2009), a contribuição deste artigo é a de reconhecer os condicionantes para a formação e a manutenção dos processos de internacionalização, enquanto uma das consequências específicas dos relacionamentos propiciados pelos clusters. Os resultados reforçam a idéia de que os fatores facilitadores e dificultadores, 
enquanto condicionantes, levam as empresas a cooperarem ainda mais na busca do conhecimento.

Assim, este trabalho justifica-se teoricamente por constituir-se em temática com envolvimento de diferentes categorias de análise, representadas pelos três conjuntos de fatores, que buscam maior compreensão sobre essa realidade complexa, podendo servir de sugestão e apoio a estudos futuros pelas características do contexto da pesquisa, bem como, por seus resultados. Além disso, utiliza do modelo de práticas estratégicas graduais e processuais em um ambiente de formação do conhecimento e de internacionalização nas organizações para discutir a abordagem da colaboração na rede (Rezende e Versiani 2007; Child e Rodrigues 2006). Este trabalho também tem relevância para os gestores dos clusters e das empresas participantes, para as instituições governamentais e não governamentais ali atuantes, principalmente pelas considerações referentes à atuação coletivizada. Destaca-se inclusive a relevância dos clusters como geradores de emprego e renda e afetando praticamente toda a população de suas comunidades.

A seguir, em busca de um modelo conceitual para esta investigação, são apresentadas as principais definições utilizadas como referência para a análise dos dados.

\section{Redes de cooperação enquanto condicionante endógeno da competitividade de clusters}

As mudanças nos paradigmas tecnológicos de produção industrial interferem em todos os demais aspectos da produção e em importantes campos da organização social, com mudanças importantes na produção contemporânea do espaço. Como destaca Diniz (2006, p.1), "inaugura-se, de forma dialética, um espaço de fluxos sobre o espaço de lugares, no qual o espaço de fluxos subordina o espaço de lugares, mas é, ao mesmo tempo, por este condicionado ou determinado, criando uma economia ou sociedade em rede".

Castells (2006, p.251) segue o raciocínio e acrescenta que a formação de redes fundamenta-se na ideia de aliança e cooperação. Neste caso, a "cooperação não é apenas uma maneira de dividir os custos e recursos, mas constitui uma apólice de seguro contra alguma decisão errada". O autor argumenta que o enfoque das redes de cooperação situa-se na visão na qual "a cooperação e os sistemas de rede oferecem a única possibilidade de dividir custos e riscos, bem como manter-se em dia com a informação constantemente renovada" (CASTELLS, 2006, p.232).

Para Balestro (2004, p.52), as "redes são consideradas arranjos interorganizacionais que formam uma estrutura própria mais do que uma forma híbrida de organização entre hierarquia e mercado". Dessa forma, que as redes são estabelecidas a partir das 
interações entre as organizações e indivíduos, devendo possibilitar o alcance dos interesses tanto individuais quanto coletivos, existindo "um equilíbrio entre autonomia e dependência" (Balestro 2003, p.53).

Paiva (2007, p.20) complementa que as mesmas "consistem nas relações estabelecidas entre duas ou mais empresas, que unem know how e forças em favor de um objetivo comum". O autor ainda destaca, com base em Castells (2006), que, na concepção de redes de cooperação, é essencial considerar dois relevantes atributos: a conectividade, isto é, a comunicação eficiente entre os agentes participantes da rede e a coerência, representada pelo compartilhamento de metas e objetivos comuns.

Tálamo (2008, p.34) confirma "os atores da rede de cooperação estabelecem elos de ligação entre si e esta ligação é que define a estrutura em forma de rede e sua taxonomia". Em outras palavras, vislumbra-se que o aspecto fundamental para o entendimento das redes de cooperação situa-se "exatamente no padrão das conexões entre os atores [...] pois é este padrão de conexão ou interação que viabiliza o fluxo de informações e consequentemente, o fluxo do conhecimento e do aprendizado (Tálamo 2008:34).

A noção de desenvolvimento das redes de cooperação é percebida por Scherer e Zawislak (2007, p.4-5) com base em três etapas temporais: a constituição, ou seja, fase em que se "realizam esforços para prospecção da cooperação, constituição e formalização legal" da rede; a consolidação, etapa em que o foco concentra-se nos esforços para "qualificação dos processos de gestão das operações" e do processo administrativo; e por fim a fase da evolução, período em que a rede "já apresenta um sistema de gestão consolidado e o processo de coordenação funcionando para garantir a efetiva cooperação entre os associados".

Quando se analisa a dinâmica do desenvolvimento local, percebe-se a cooperação como um elemento fundamental. Em especial, a cooperação faz com que o cluster ganhe força e eficiência, além de intensificar o ritmo de introdução de inovações. Sob esta ótica, o aglomerado aliado à visão de cooperação reforça o potencial e o desempenho competitivo das empresas ali inseridas (Balestro 2004; Cunha e Cunha 2006; Czajkowski 2009).

Casarotto Filho e Pires (2001, p.38) citam em seus estudos as principais peculiaridades da cooperação, considerando-a como algo "tão irreversível como a globalização". A cooperação, na visão genérica de seu significado, é definida como o ato de se "trabalhar em comum, envolvendo relações de confiança mútua e coordenação, em níveis diferenciados, entre os agentes" (Lastres e Cassiolato 2005:9). 
O que se nota, portanto, é que a cooperação permite a visão do abandono do individualismo, ênfase na tolerância e no saber ceder, além da aceitação do concorrente como semelhante. Vale ressaltar que a cooperação necessita de, segundo Casarotto e Pires (2001:9): troca de informações entre várias empresas, restabelecimento de um intercâmbio de ideias, desenvolvimento de visão estratégica, definição de áreas de atuação, análise conjunta dos problemas e solução em comum, definição das contribuições dos parceiros.

As redes interorganizacionais apresentam variadas tipologias. Neste sentido, Balestrin e Vargas (2004:07) utilizam o modelo de orientação conceitual de Marcon e Moinet (2000) para analisar "as principais dimensões sobre as quais as redes são estruturadas". Os autores citados classificam as redes interorganizacionais em quatro tipos principais: (1) redes verticais (dimensão da hierarquia); (2) redes formais (dimensão contratual); (3) redes informais (dimensão da convivência) e (4) redes horizontais (dimensão da cooperação).

Woitchunas e Sausen (2005, p 9) pautam seus estudos na relação positiva existente entre a consolidação de redes de cooperação e o desenvolvimento local e regional. Esses autores defendem que "as redes de cooperação surgem como uma estrutura de articulação capaz de aumentar a competitividade das empresas, interferindo ativamente nos rumos do setor, pelo menos na região em que está presente esta forma de estruturação.".

Nesta perspectiva, as redes de cooperação são estruturas resultantes do relacionamento cooperado entre seus atores, enfatizando o enfoque coletivo, a troca de informações e os objetivos comuns. As redes de cooperação oferecem suporte para coordenação e articulação de projetos conjuntos entre os atores em prol do desenvolvimento de um aglomerado (Amato Neto 2000; Carrão 2004; Gerolamo 2007; Czajkowski 2009).

Complementam-se ainda, com base em Verschoore e Balestrin (2006), os principais fatores competitivos das redes de cooperação: ganho de escala e poder de mercado, provisão de soluções, aprendizagem e inovação, redução de custos e riscos e o fator relações sociais (ampliação da confiança e acúmulo de capital social).

Ao estudar a importância dos clusters e os benefícios que a cooperação proporciona aos agentes inseridos nos mesmos, verifica-se que, em decorrência da relevância de se agir coletivamente, a questão da governança deve ser mencionada. Balestro (2004) salienta que a governança permite observar de que forma as relações de cooperação entre os agentes se desenvolvem e se estruturam nos clusters. 
No caso das redes de cooperação, Balestro (2004) afirma ainda que a governança é essencial, pois as relações de cooperação entre os agentes de um aglomerado estruturam-se com base numa visão de longo prazo. Dessa forma, destaca-se que [...] a governança de rede implica a existência de um grupo específico, persistente e estruturado de empresas autônomas (bem como agências sem fins lucrativos) envolvidas na criação de produtos ou serviços baseados em contratos implícitos e abertos, em condições de adaptar-se às contingências ambientais e coordenar e salvaguardar as trocas. Tais contratos são elos de ligação sociais e não legais (Candance et al. 1997 apud Balestro 2004:51).

Diante da afirmação de Balestro (2004), defende-se a ideia de que nas redes de cooperação é essencial que haja uma estrutura entre os atores e o estabelecimento de mecanismos de governança e normas, os quais orientam e coordenam o empreendimento das ações coletivas. O "sucesso do funcionamento das redes não está apenas no seu desenho contratual, mas na formação das normas que regulam as interações entre as empresas" (Balestro 2004:54).

A governança em uma rede de cooperação pode ocorrer por meio de uma central de coordenação, isto é, uma "entidade composta por profissionais de fora das empresas ou por representantes das empresas, com a finalidade de monitorar as relações entre as empresas e gerenciar o processo de tomada de decisão coletiva" (Balestro 2004:61). Dessa forma ressalta-se que a gestão de uma rede de cooperação necessita de uma estrutura de coordenação e mecanismos de governança.

A análise de rede pode ser aplicada em estudos de diferentes enfoques (econômico, social, ambiental), diferentes escalas (local, regional, nacional, global), diferentes objetivos (redes de informação, redes produção, redes organizacionais, redes de cooperação solidária, redes comunitárias, etc.). Esta representação revela que muitas unidades quando inseridas em uma rede são capaz de originar uma nova ordem, que não pode ser entendida apenas por suas unidades individuais, mas uma nova arquitetura que se distingue por ser dinâmica na sua estrutura e relações e por ser original e única no seu design. Portanto, novos estudos de redes de cooperação, revelam novos componentes, novos artefatos e novos elementos que agregam novos conceitos e construtos a teoria (Cunha e Cunha 2005).

\section{Clusters: uma abordagem de aprendizagem e de inovação nas práticas relacionais enquanto condicionantes da internacionalização}

Todas as abordagens sobre clusters, tais como, arranjos produtivos locais, distritos industriais, aglomerações de Porter, milieux inovativos e redes sociais têm como elemento comum a possibilidade de proporcionar a absorção do conhecimento entre os 
agentes em suas relações sociais de produção. O conhecimento adquirido internamente pode ser considerado como consequência das relações entre todos os agentes que mantêm algum tipo de relação com a organização. Na visão de Maskell, Bathelt, Malmberg (2005), as empresas clusterizadas para se tornarem competitivas internacionalmente, além de intensificar as relações no cluster, necessitam desenvolver canais com agentes externos para permitir o fluxo de conhecimento, aprendizagem e capacitação tecnológica.

Geralmente os estudos dos relacionamentos interorganizacionais dão ênfase aos condicionantes enquanto causas e contingências que induzem à formação desses relacionamentos. São os condicionantes, apontados por Oliver (1990), que atuam como motivador ou como sustentáculo para o aumento da probabilidade de que essas diferentes contingências causem a ocorrência do estabelecimento e a manutenção das relações.

Os autores citados destacam a importância das relações entre os próprios participantes e entre empresas de redes externas como crucial para a aquisição, criação e difusão do conhecimento para as suas empresas. A combinação entre as relações internas e as relações externas, quando existente, gera conhecimento, aprendizagem e inovação, constituindo-se em condição importante para a internacionalização das empresas. Essas relações podem ser consideradas como fonte privilegiada de aquisição de conhecimento, estimulada pela proximidade geográfica e tecnológica. A proximidade favorece a complementaridade tecnológica, as interdependências socioculturais, o fluxo de informação, o conhecimento e a capacitação tecnológica das empresas. Estudos contemporâneos, entretanto, destacam que a proximidade física deixa de ser relevante em privilégio de outros condicionantes relacionais, tais como a confiança e o compromisso com a busca por novas oportunidades em mercados internacionais (Johanson e Vahlne 2009).

\section{Clusters: fatores exógenos enquanto condicionantes da internacionalização}

Olivares (2003) aponta os fatores exógenos como o ambiente, a estratégia, os avanços tecnológicos e a cultura enquanto influenciadores do surgimento e a consolidação das possibilidades relacionais. Esses laços permitem administrar as incertezas ambientais e atender às necessidades de recursos, para dividir custos e os riscos de um projeto. Do mesmo modo, as vantagens geradas pelas relações oportunizadas pelo cluster constituem-se em externalidades positivas para os seus participantes. Na medida em que o aumento do número de parceiros, a maior cooperação entre eles e os efeitos do aprendizado interno tornam estas empresas mais capacitadas para se tornarem mais competitivas, também ampliam seus canais de relacionamento com a economia global e desenvolvem fortes conexões com outros clusters internacionais, reproduzindo novas 
relações de aprendizagem, de conhecimento e de contínua capacitação (Facco e CUNHA 2009).

\section{Clusters: fatores endógenos enquanto condicionantes da internacionalização}

Grande parte da literatura referente aos fatores endógenos destaca a disponibilidade ou a ausência de informação enquanto facilitadores e dificultadores significativos para a constituição das comunidades em termos de imersão posicional entre as empresa (Gulati e Garciulo 1999). Outra variável endógena significativa a ser considerada no processo de internacionalização diz respeito à influência da inovação na internacionalização. É possível observar algumas pesquisas cujos resultados têm mostrado que a inovação tem impactado de forma positiva e significativa a internacionalização, isto é, a inovação aumenta a probabilidade de a empresa exportar (Facco e Cunha 2009: Gonzalez e Cunha 2011: Mendonça e cunha 2011). Porém, o enfoque sobre a relação entre inovação e internacionalização, segundo Filipescu (2007), tem sido pouco explorado e, consequentemente, há poucos estudos empíricos que exploram essa relação de forma recíproca.

Arbix et al. (2004), pesquisadores do Instituto de Pesquisa Econômica e Aplicada (IPEA), utilizando dados nacionais tais como Pesquisa Industrial Anual (PIA), do Instituto Brasileiro de Geografia e Estatística (IBGE); da Relação Anual de Informações Sociais (RAIS), do Ministério do Trabalho e Emprego (MTE); da Secretaria de Comércio Exterior (SECEX) do Ministério de Desenvolvimento, Indústria e Comércio Exterior (MDIC); e da Pesquisa Industrial de Inovação Tecnológica (PINTEC), também do Instituto Brasileiro de Geografia e Estatística - IBGE -, consideram haver evidências de que o desempenho exportador pode ser influenciado positivamente quando a firma estabelece uma subsidiária no exterior. Tal subsidiária pode contribuir com o desempenho exportador da empresa por exercer diversas funções, tais como: acessar canais de comercialização, adaptar os produtos à demanda de mercados específicos, criar mercados, acessar recursos financeiros mais baratos e apropriar tecnologias não disponíveis no mercado doméstico. Desta forma, os autores acima citados buscam evidências sobre qual é a influência da internacionalização com foco na inovação tecnológica sobre o comércio exterior de firmas na indústria brasileira. Sugerem evidências de que há um alcance de $90 \%$ no valor adicionado na indústria. Esses autores identificam que as empresas internacionalizadas, com foco na inovação são maiores, possivelmente aproveitam de maneira mais eficiente os rendimentos crescentes de escala e se inserem no comércio internacional de maneira mais intensa, pois exportam e importam mais que as outras categorias de firmas. Além dessas características, foi possível observar que elas remuneram melhor a mão de obra, porque muito provavelmente são mais produtivas, empregam pessoal com maior escolaridade e, possivelmente, fazem algum tipo de 
treinamento para o seu pessoal ocupado (Arbix et al. 2004). Observam ainda que as empresas que realizam internacionalização com foco na inovação, a probabilidade dessa ser exportadora é maior que na categoria das empresas que não utilizam outras organizações como fonte de informação para a inovação tecnológica.

Em outra pesquisa divulgada pelo IPEA, cujo objetivo é verificar qual a importância da inovação tecnológica para tornar uma firma exportadora na indústria brasileira, De Negri (2005) aponta que, em relação à inovação, a variável mais importante para determinar se a firma é ou não capaz de inserir-se no comércio internacional é a inovação de produto para o mercado doméstico, a qual aumentaria em $17 \%$ a probabilidade da empresa exportar, em relação àquelas firmas que não são inovadoras. A mesma autora conclui que inovar em produtos pode ser um fator importante para tornar a empresa capaz de concorrer em outros mercados. Em relação às inovações de processo para o mercado, De Negri (2005) sugere que aumenta em mais de $9 \%$ a probabilidade da firma inovadora exportar. Essas inovações podem aumentar a eficiência da firma e reduzir seus custos, o que aumenta sua competitividade no comércio internacional. Por fim, identifica que a fabricação de um novo produto já existente no mercado também tem impactos positivos, porém menores, com $8,8 \%$ na probabilidade de a empresa ser exportadora.

Eusebio Rialp (2002), investigando o grau de influência das diferentes atividades de inovação tecnológica sobre a probabilidade e a intensidade exportadora das empresas espanholas do setor têxtil, em termos do percentual das vendas advindas do mercado internacional, confirmaram a relação significativa entre o investimento em pesquisa e desenvolvimento sobre a probabilidade de a empresa começar a exportar. Igualmente, López e García (2004) e Filipescu (2007), em outros estudos, analisando a influência da capacidade tecnológica da empresa sobre a decisão de exportar e sobre a intensidade exportadora, mostraram que as inovações de produto e processo influenciam positiva e significativamente tanto na decisão de exportar como na intensidade exportadora.

Mesmo com a existência de limitações, a perspectiva da dependência dos recursos entende, em sua perspectiva mais ampla, que nenhuma organização é capaz de gerar todos os recursos de que necessita e que nem toda atividade pode ser realizada somente internamente de maneira isolada e independente (Hall 2004). As organizações passam a depender do seu ambiente e de outras organizações como forma de obter o acesso aos recursos necessários. Aldrich (1979) acrescenta que a competição por recursos escassos, leva à dependência de algumas organizações em relação a outras. Essa perspectiva tem como elemento básico a escolha estratégica. A perspectiva da estratégia, por sua vez, considera as ações coletivas como uma das muitas oportunidades estratégicas que podem ser exploradas quando se busca melhorar a posição de uma organização perante seus competidores. Nesse caso, a atenção é direcionada à necessidade de ajustar as 
respectivas estratégias entre os parceiros para que o relacionamento contribua positivamente para o alcance dos objetivos de cada uma das partes, assim como aprender a operar em novos mercados domésticos ou externos ou para inovar e diversificar em novos negócios (Child e Faulkner 1998; Pfeffer e Salancik 1978; Hall 2004; Facco e Cunha 2009; Auster 1994; Castro 2007). Os ajustes estratégicos dados pelas práticas no cluster e os seus resultados são destacados por esses autores como relacionados à posição estratégica de seus participantes em relação à competitividade e às condições difíceis de mercado e suas incertezas.

Nesse contexto, de busca por recursos de modo coletivo e tendo como foco a aprendizagem inovadora, é conveniente a explicação de Argyris e Schön (1982) sobre aprendizagem organizacional propondo que a sua efetividade ocorre quando a organização tem a capacidade de identificar elementos facilitadores e dificultadores, ou aqui representados pelos condicionantes para a internacionalização a partir de um contexto prévio para aprender. Em um cenário de mudanças, o desafio para a organização é selecionar informações úteis ao seu processo de formação e a comunicação dos conhecimentos aos seus participantes. Adotando-se aqui a abordagem de Davenport (1998), verifica-se que, à medida que as organizações aprimoram a sua capacidade de distinguir entre dados, informação e conhecimento, estarão gradativamente selecionando conhecimentos que de fato agregarão valor ao processo de aprendizagem e, portanto, ao de inovação e diversificação para a internacionalização.

Assim, por entender-se que um dos desafios dos clusters de pequenas empresas seja adquirir uma nova forma de trabalhar cooperativamente para competir no mercado internacional, através da sinergia de recursos, a questão da aprendizagem emerge enquanto um conjunto de atividades ou práticas situadas enquanto construção social. Nessa perspectiva, Engestron $(1991,2001)$, Wenger $(1987,1998)$ e Balbinot et al. (2007) sugerem o desafio de se investigarem as condições que predispõem a atuação de lideranças na construção de cultura comum que garanta a transmissão de conhecimento e que por sua vez facilite o sucesso para a cooperação das empresas internacionalmente. Por sua vez a construção do conhecimento, sugerida por Vigotsky (1978) implica uma ação partilhada, demandando cooperação e troca de informações, com consequente ampliação das capacidades individuais.

Engestron (2001) sugere que essa análise pode ser orientada por quatro questões básicas: a) Quem são os sujeitos que aprendem e como eles são definidos e localizados? b) Por que eles aprendem e o que os leva a fazer o esforço? c) O que eles aprendem e quais os conteúdos e os resultados da aprendizagem? d) Como eles aprendem e quais as ações chave ou processos de aprendizagem? A partir dessas respostas emerge o 
pressuposto - com a aprendizagem compartilhada as empresas desenvolvem melhores estratégias para a internacionalização de seus negócios.

\section{Fatores e práticas orientadas para o processo de internacionalização}

A internacionalização acontece ao se buscarem novas oportunidades por meio do entendimento sobre novos mercados e no envolvimento crescente dessas empresas em atividades de internacionalização e tem seu início na identificação das várias modalidades de entrada nos mercados externos (Welch e Luostarinen 1988). Essas atividades dependem das relações interorganizacionais com parceiros confiáveis e comprometidos com esse processo para a captação de oportunidades existentes fora do país de origem. Os parceiros podem estar em localidades próximas às empresas ou mesmo no exterior. Geralmente a sua definição se dá em função dos benefícios, dos custos e dos riscos para se determinarem as vias e condições de internacionalização mais apropriadas à empresa (Johanson e Vahlme 2009). Para Carlson (1975) e Johanson e Vahlne (2009), a internacionalização também é considerada como um processo de natureza incremental, baseado em aprendizagem e conhecimento, em termos de aprender por meio das relações interorganizacionais e menos como consequência de etapas deliberadas e planejadas. Para Andersson (2000), uma das principais contribuições dessa abordagem é a de assumir a racionalidade limitada dos indivíduos e concomitantemente direcionar-se ao comportamento organizacional ao se internacionalizar, assumindo que o processo também envolve aprendizagem.

Nesse sentido, a internacionalização é um processo de etapas incrementais nas quais a empresa, a partir do aprendizado e da captação de recursos obtidos com a expansão de seu mercado, utiliza diferentes modos de entrada, iniciando por um simples processo de exportação indireta via representante (local ou internacional), contratos de parceria internacional, alianças com ou sem investimento até o envolvimento total via aquisição ou Green Field (Cavusgil 1980; Root 1984).

Seguindo o mesmo raciocínio, Cavusgil (1980) considera que essa forma processual da internacionalização surge das grandes incertezas, dos elevados custos com informação e também da falta de conhecimento empírico sobre o mercado, principalmente em empresas de pequeno e médio porte. No ponto de vista desse autor, a exportação é uma espécie de inovação para essas organizações, devido ao alto grau de incerteza envolvido na operação que apenas será reduzida adquirindo-se experiência. Entretanto, na prática, Benito, Petersen e Welch (2009) salientam a discrepância entre a teoria e o efetivo comportamento nos processos de internacionalização das empresas destacando a necessidade de se pesquisar mais sobre como as empresas, de fato, escolhem os seus modos para se tornarem internacionais. 
Análises das práticas de negócios internacionais de empresas brasileiras têm-se destacado pelo predomínio do pessimismo exportador existentes nos modelos mentais e cultural na concepção da colaboração interorganizacional e na busca por fontes de novos negócios e conhecimentos. Esses aspectos, juntamente com as práticas de mercado e de negócios limitados ao local, têm sido apontados como fatores responsáveis pela grande deficiência competitiva das empresas brasileiras nos mercados internacionais (Furtado 2004; Judice 2006).

Nesse contexto, de relacionamento interorganizacional enquanto um dos principais fatores de aprendizagem e inovação e consequentemente de capacitação para o aproveitamento das oportunidades de busca por novos mercados. Grandori e Soda (1995) apontam mecanismos de coordenação utilizados para sustentar essa condição em diferentes níveis e graus: a) comunicação aberta; b) normas sociais e de integração do grupo; c) formação de grupos de coordenação; d) planejamento e controle formal; e) sistema de incentivos; f) sistema e normas de seleção de participantes; g) sistema de informações; h) apoio de entidades públicas e infraestrutura. Candido e Abreu (2004) após estudo exploratório em agrupamentos industriais de pequenas e médias empresas brasileiras, com o objetivo de identificar e validar um conjunto de fatores críticos de sucesso no processo de formação, desenvolvimento e manutenção de redes interorganizacionais aponta, especificamente, como variável do processo de formação: 1) familiarização com os conceitos e vantagens da nova forma de atuação; 2) escolha adequada dos agentes participantes; 3) existência de líderes nos agrupamentos; 4) definição da arquitetura organizacional da rede; 5) relacionamentos voluntários e constantes; 6) vinculação a uma política de desenvolvimento regional; 7) foco em atividades com conhecimento e potencial para a colaboração; 8) remoção dos obstáculos, restrições e limitações; 9) desenho das fronteiras organizacionais; 10) estratégia de atuação e políticas mercadológicas; 11) estratégias para o gerenciamento das informações. Para acessar esses mecanismos podem combinar diferentes atividades que se desenvolvem no grupo, tais como de gestão, de mercado, de técnicas e de operações.

O conhecimento gerado a partir de fontes externas, ou mesmo das empresas individualmente e compartilhadas no grupo, podem ser integrados ao processo estratégico pretendido de cada uma das empresas, assim como para a governança do grupo que contribui para a sua disseminação. Entretanto, existem fatores que podem limitar a sua viabilidade. Por exemplo, Thomaz et al. (2009), em um estudo de caso, identificaram que a existência de cooperação não elimina os fatores presentes da competição entre os atores de um cluster. A maturidade do negócio e o esgotamento do mercado local podem acelerar a competição entre as empresas participantes. Assim como, o maior desenvolvimento de algumas empresas em relação a outras, pode 
acarretar desequilíbrios de forças entre empresas do mesmo elo na cadeia produtiva ou entre elos da cadeia e, com isso, se percebe o aumento da competição, com possível redução das condições cooperativas. Os autores acima citados identificaram também as dificuldades para a aquisição de conhecimento quando não se encontram as condições existentes para esse fim, resultando para os participantes do arranjo apenas informações básicas sobre produtos e obtidas na dependência dos fornecedores.

\section{Metodologia: aproximação entre as categorias de análise}

Entende-se, para efeito desta investigação e com base nos fundamentos anteriores, que (1) práticas relacionais, os (2) fatores endógenos, e os (3) fatores exógenos existentes na comunidade de empresas de um cluster podem contribuir com os processos inovadores e complexos existentes nas práticas organizacionais e, especificamente neste trabalho, nos processos de internacionalização. Desse modo, os condicionantes do processo de internacionalização são definidos, de modo geral, como os facilitadores e os dificultadores ambientais e internos que podem alterar as condições das empresas se internacionalizarem, ou não. Assim, pergunta-se quais fatores estão presentes nesses três grupos de condicionantes que delineiam as bases para a formação dos processos de internacionalização das empresas dos clusters pesquisados?

Visando à aproximação das categorias de análise, as etapas da pesquisa constituem-se em:

1) Identificar as práticas relacionais orientadas para a internacionalização existentes.

2) Caracterizar os condicionantes exógenos dos processos de internacionalização.

3) Caracterizar os condicionantes endógenos dos processos de internacionalização.

\section{A pesquisa}

Considerando o propósito da pesquisa, os cinco clusters foram selecionados por tipicidade, relevância socioeconômica regional, acessibilidade e por proverem os condicionantes para a internacionalização de suas empresas. A coleta de dados utilizou a perspectiva transversal, como nível de análise os clusters e as empresas e como unidade de análise os dirigentes dos clusters e de algumas das empresas participantes. Os dados foram coletados por meio de trinta e nove entrevistas com uso de roteiro semiestruturado, gravadas e transcritas. Também foram coletados dados, por observação não participante, das atividades dos escritórios das governanças dos clusters e de nove empresas (três do setor madeireiro, uma de confecções de Maringá, uma da associação de produtores de bonés de Apucarana, uma do arranjo de Francisco Beltrão e três do cluster de metais de Loanda). Foram realizadas análises documentais com a utilização de relatórios, atas de reuniões, atos de constituição e normatizações existentes nas governanças de cada um dos clusters. Os dados foram coletados durante nove 
meses divididos entre os cinco clusters e se referem aos anos de 2008 a 2009. De acordo com a natureza da investigação, os dados utilizados foram provenientes de fontes primárias (entrevistas e observação) e fontes secundárias (análise documental). A relevância dos dados primários foi constatada por esgotamento, ou seja, foram coletados até serem observadas repetições nas respostas obtidas dos entrevistados.

A coleta de dados foi realizada em duas etapas. Primeiramente foram obtidos os dados secundários a partir das informações disponibilizadas na Federação das Indústrias do Paraná/Brasil e documentos existentes nos escritórios dos clusters, como atas e relatórios. Foram obtidas informações que permitiram uma compreensão inicial dos casos estudados. Na segunda etapa, esses dados iniciais foram complementados com entrevistas informais com pessoas que atuam nas entidades de apoio aos arranjos como o Serviço Brasileiro de Apoio a Micro e Pequena - SEBRAE - e da própria Federação das Indústrias do Paraná - FIEP. Isso permitiu o desenvolvimento da pesquisa para a fase de coleta dos dados primários com imersão no campo empírico. A primeira fase durou aproximadamente quatro meses, e a segunda aproximadamente cinco meses.

As entrevistas foram feitas com três dirigentes da associação que constitui o cluster de confecções de Maringá, seis do madeireiro, um de confecções de Francisco Beltrão, um do cluster de metal de Loanda e cinco de confecções de bonés de Apucarana. O restante das 23 entrevistas foi realizado com dirigentes das empresas participantes, que ao mesmo tempo são os seus proprietários conforme resumido na Tabela 1. A maioria dos dirigentes das empresas, inclusive os dirigentes das associações, são os fundadores das empresas. Com exceção de seis dos dirigentes, cinco assumiram a empresa da família e um a adquiriu após seis anos de fundação. Nove dos entrevistados possuem curso superior. O restante concluiu o curso secundário e todos realizaram diversos cursos técnicos relativos ao seu negócio ou atividade principal.

\begin{tabular}{|l|l|l|l|r|}
\hline Cluster & Localidade & Produtos principais & $\begin{array}{l}\text { Numero de } \\
\text { Empresas } \\
\text { envolvidas }\end{array}$ & $\begin{array}{l}\text { Empresas em } \\
\text { processo de } \\
\text { internacionalização }\end{array}$ \\
\hline Confecções & Maringá e região & Vestuário & 91 & 12 \\
\hline Confecções & $\begin{array}{l}\text { Francisco Beltrão e } \\
\text { Região }\end{array}$ & Vestuário & 109 & 19 \\
\hline $\begin{array}{l}\text { Confecções } \\
\text { bonés }\end{array}$ & Apucarana e região & $\begin{array}{l}\text { Bonés e } \\
\text { camisetas }\end{array}$ & 576 & 24 \\
\hline Mobiliário & Arapongas e região & Móveis & 34 & 72 \\
\hline $\begin{array}{l}\text { Metais } \\
\text { Sanitários }\end{array}$ & Loanda & $\begin{array}{l}\text { Torneiras e } \\
\text { acessórios }\end{array}$ & & 6 \\
\hline
\end{tabular}

Fonte: dados da pesquisa

Quadro 1: Características dos Clusters Pesquisados 
Os dados foram triangulados entre si como forma de ampliar a segurança na sua interpretação (YIN, 2001) por meio de análise dos conteúdos discursivos, documentais e registros das observações. Os dados depois de transcritos foram submetidos à técnica de análise temática obtidas dos eventos dialógicos das entrevistas em que foi possível identificar as práticas individuais e coletivas estratégicas nos processos de internacionalização. A seguir iniciou-se a análise de conteúdo utilizando, em conjunto, os dados primários e secundários, com a finalidade de obter inferências em temáticas. Esses temas foram relacionados aos seus significados compartilhados para cada uma das categorias de análise da proposta.

$\mathrm{Na}$ descrição da análise e discussão dos resultados da pesquisa são inseridas frases obtidas das várias entrevistas com destaque entre aspas com a finalidade de ilustração e facilitar a descrição da análise. As referências sobre os clusters ora são feitas como APL ora como rede ou associação seguindo a denominação dos entrevistados.

\section{Análise e Discussão dos Resultados}

A seguir apresenta-se a análise e a discussão dos dados em termos (1) das práticas relacionais orientadas para a internacionalização, os (2) condicionantes endógenos e os (3) condicionantes exógenos, finalizando com sugestões para futuras investigações. Os dados qualitativos de maior destaque e obtidos das entrevistas e observações são apresentados em itálico descrevendo as percepções e as práticas promovidas pela governança dos clusters e dirigentes das empresas.

\section{Práticas relacionais significativas}

Os dados da pesquisa apontam algumas das práticas relevantes promovidas pelas governanças e pelos próprios participantes dos clusters no sentido de criar relações significativas que possam disseminar a confiança e que orientam os seus participantes ao processo de aprendizagem sobre os fatores que podem afetar a capacidade de busca e de exploração de novas oportunidades, assim como a internacionalização de suas empresas. Pois, conforme observado por Talamo (2008) e Casarotto e Pires (2001, p.39), a troca de informações, o intercâmbio de ideias, o desenvolvimento de visão estratégica, a definição de áreas de atuação, a análise conjunta dos problemas e solução em comum, a definição das contribuições dos parceiros é o que constitui a rede de cooperação.

Segundo dados da pesquisa

"São promovidas reuniões informais para a aproximação social dos empresários".

"Objetiva-se inicialmente a troca de informações para, num segundo momento, procurar a participação da governança para a consolidação de iniciativas que venham a conduzir a alguma aprendizagem entre os participantes e assim consolidar ações colaborativas mais consistentes". 
Nesses encontros são também previstas reuniões periódicas para a atualização do planejamento estratégico e operacional. Na posição de um dirigente do cluster moveleiro

"Na última reunião do ano estiveram presentes 78 empresários" quando "foram apresentados aos novos participantes os canais coletivos de comunicação, como o jornal e o site". "Por esses canais as atividades e decisões tomadas pela coordenação do APL são informadas para todas as empresas facilitando a disseminação das informações a respeito das experiências das empresas e dos seus resultados".

Nos grupos as atividades coletivas de aprendizagem e troca de conhecimentos são projetos cooperativos que ocorrem entre as empresas e as várias entidades com atuação efetiva ao longo do tempo, tais como os sindicatos, as entidades governamentais, os governos estaduais e municipais. Assim, afirma um dos participantes deste mesmo cluster:

"A maioria das empresas que participa do sindicato (entidade sindical no qual participam empresas do arranjo), de modo geral, são as que possuem mais de 19 empregados e, assim, podem recorrer a consultorias e ao SENAI (Serviço Nacional da Indústria) para solução de problemas de ordem operacional e tecnológica. O SEBRAE (Serviço Brasileiro de Apoio as Micro e Pequenas Empresas) contribui com o desenvolvimento de cursos na área de gestão".

Identificou-se que as ações promovidas pela governança dos clusters, como a participação em feiras, a leitura de matérias de revistas especializadas e o acompanhamento das informações do setor, são percebidos como importantes na disseminação do conhecimento para a comunidade de modo geral. Esses dados somados aos dados secundários levantados pela pesquisa sugerem quatro agrupamentos ou perfis comportamentais orientados para as práticas relacionais que promovam a aprendizagem e, consequentemente, que possam promover a internacionalização das empresas. Esses aspectos podem ser somados de modo distinto à colaboração de Scherer e Zawislak (2007) com a especificação de diferentes padrões de conexão entre os empresários envolvidos nos clusters (Talamo 2008).

PERFIL 1: Empresas que não se relacionam com a finalidade de trocar experiências e conhecimento entre si

Observa-se, em todos os clusters que o relacionamento entre as empresas em busca de troca de experiências e aprendizagem para a internacionalização não se dá de forma fácil e natural. Ao contrário observa-se principalmente

"a falta de participação nas ações de integração promovidas pela governança do APL por parte de muitas das empresas".

Um aspecto promotor da não proximidade entre os empresários diz respeito à noção persistente da concorrência entre as próprias empresas participantes do cluster, que segundo os entrevistados 
"os integrantes tem como referência apenas o mercado local"; e, a "distância geográfica entre os municípios e empresas também concorre como um dos fatores dificultadores para a integração".

Observa-se que o grupo de empresas não participante é representado pelo maior número de empresas de todos os clusters da pesquisa, sendo na sua maioria constituído de micro e pequenas empresas.

PERFIL 2: Empresas que participam de algumas atividades relacionais, mas não colaboram com a troca de informações

Indagados sobre a troca de informações, afirmam os participantes:

"Os integrantes embora participem de algumas atividades relacionais não colaboram na troca de informações"; "Esperam por comunicados, experiências e benefícios das demais, mas não atuam colaborativamente". "Embora o grau de pessoas que não colaboram na troca de informações seja pequeno (....) eles exercem influência negativa na percepção dos demais, prejudicando a disseminação da confiança entre os demais participantes".

PERFIL 3: Pequenos grupos de empresas que atuam colaborativamente entre si e paralelamente ao grande grupo de empresas dos clusters

Questionados sobre as relações de colaboração, os integrantes afirmam:

"Não necessariamente as relações de colaboração ocorrem em paralelo à governança do APL".

Essas relações atuam através de "orientações próprias em um grupo constituído pela confiança" "construída" com o passar do tempo "entre eles", ou por meio de uma das entidades agregadoras para a promoção da troca de experiências e aprendizagem,

"principalmente em conhecimentos operacionais, a troca de materiais, revisão de custos e o empréstimo de equipamentos". "Esses grupos são representados, geralmente, por um número pequeno de empresas, de três a cinco".

PERFIL 4: Empresas com atividades de relacionamento e colaboração estratégica intensiva com outras empresas e entidades

Os dados indicam que participando coletivamente na busca por inovações, novos mercados e

"atuando com centrais de compras e cooperativas de exportação" em conformidade com as definições de aprendizagem relacional.

"Há a troca intensiva de experiências e inovações em nível de produto e de mercado." "Poucas empresas participam dessa etapa alvo."

Os quatro perfis são apresentados na Tabela: 


\begin{tabular}{|c|c|c|}
\hline RELACIONAM-SE COM O CLUSTER & $\begin{array}{l}\text { Perfil 2: Grupo diversificado de } \\
\text { empresas - } \\
\text { Relacionamento no cluster, mas } \\
\text { não colaboram com informações } \\
\text { de interesse coletivo }\end{array}$ & $\begin{array}{l}\text { Perfil 4: Empresas de médio porte } \\
\text { com experiências coletivas de } \\
\text { aprendizagem - } \\
\text { Troca intensiva de informações e } \\
\text { aprendizagem }\end{array}$ \\
\hline $\begin{array}{l}\text { NÃO SE RELACIONAM COM O } \\
\text { CLUSTER OU RELACAO PARCIAL }\end{array}$ & $\begin{array}{l}\text { Perfil 1: Maioria das empresas de } \\
\text { micro e pequeno porte - } \\
\text { Não se relacionam no cluster e não } \\
\text { trocam informações }\end{array}$ & $\begin{array}{l}\text { Perfil 3: Grupo diversificado de } \\
\text { empresas - } \\
\text { Grupos paralelos com troca de } \\
\text { informações }\end{array}$ \\
\hline
\end{tabular}

Fonte: Dados da pesquisa

Tabela 2: Perfis comportamentais referentes às atividades relacionais

Esta representação obtida dos dados da pesquisa colaboração com Cunha e Cunha (2005 A) revelando que, muitas empresas quando inseridas em uma rede de colaboração e de aprendizagem, origina uma estrutura relacional distinta que permite uma nova ordem. Ela, segundo os autores, não pode ser entendida apenas por suas unidades individuais, mas uma nova arquitetura que se distingue por ser dinâmica na sua estrutura e relações e por ser original e única. Revelando novos componentes, novos artefatos e novos elementos que agregam novas questões de pesquisa relacionadas ao tema.

\section{As práticas orientadas para a internacionalização}

A maior parte das empresas que fazem parte dos clusters pesquisados atende ao mercado nacional. Pelos dados dos relatórios das governanças a exportação representa aproximadamente $8 \%$ da produção, de modo geral e tem apresentado forte crescimento. Apenas no cluster de vestuário de Francisco Beltrão a tendência apresenta-se pela "preferência ao mercado nacional em forte crescimento." Segundo dados obtidos dos relatórios, as vendas para o mercado externo pelo menos dobrou no conjunto dos clusters nos últimos três anos. Nesse sentido, as empresas do terceiro e quarto grupos de comprometimento descritos anteriormente, que apresentam relacionamentos orientados para a internacionalização, estão buscando capacitação para facilitar a inserção no mercado externo, diferenciando o design e a qualidade dos produtos, por meio do investimento em qualidade, modernizações dos equipamentos, lançamento de novos produtos e a busca por novos canais de comercialização.

A primeira experiência nos clusters de confecções relacionadas à internacionalização demonstra que os mecanismos colaborativos de aprendizagem ocorrem em processo e em fases tal qual sugeridos por Johansson e Vahlne $(1977,2009)$. Segundo dados das entrevistas, percebe-se que as primeiras ações de exportação para o MERCOSUL ocorreram por iniciativas individuais. No segundo momento, ações coletivas indicaram uma pré-disposição de algumas das empresas a

"trabalharem colaborativamente nos processos de internacionalização principalmente pelas facilidades na obtenção de informações de modo coletivo". 
Foram observados durante a coleta dos dados primários e secundários alguns fatores contingenciais dificultadores para uma melhor inserção dos clusters no mercado internacional, como a "valorização da moeda brasileira (o Real), reduzindo a margem competitiva das empresas quando comparadas com empresas de países asiáticos, especialmente a China". Outro fator diz respeito ao

"conhecimento dos mercados internacionais onde a maioria das organizações brasileiras de pequeno e médio porte desse setor não possui".

Aqui está presente o que os empresários chamam de "cultura exportadora" que a consideram não possuir.

Com relação às estratégias para a internacionalização, elas são formuladas e "partem sempre da estrutura de governança do $A P L "$ ou de suas lideranças, que sugerem quais são os segmentos que vão ser trabalhados, quais são os segmentos que serão explorados e como o produto ou processo deve ser feito para atender determinadas especificações. Depois disso,

"é detalhado com as empresas quais ações serão levadas adiante no processo". "Essas ações têm promovido uma maior integração entre as empresas e, conseqüentemente o aprendizado a respeito dos novos mercados."

De modo recursivo a colaboração das empresas de maior participação na colaboração e situadas no quadrante quatro fornecem os subsídios de suas melhores práticas para que a governança estenda as informações para o restante das empresas. Assim como, por exemplo: o modo mais frequente utilizado pelos clusters para inserção no mercado externo é a "utilização de agentes de exportação". Esses agentes e seus papéis são definidos pelas associações de exportação dos clusters

"onde se busca a efetiva participação em um mercado altamente complexo com demanda por produtos diversificados tanto no design como no processo de produção".

Assim, o processo de internacionalização se dá principalmente com o uso de agentes representantes no exterior e a adaptação sucessiva ocorre com a aplicação de novas técnicas de produção e design de produto. As praticas, obtidas dos bons resultados das empresas que passaram pela experiência e as disseminaram entre os participantes e orientadas para a internacionalização por cluster são apresentadas na Tabela 3. 


\begin{tabular}{|c|c|c|c|c|c|}
\hline Cluster & $\begin{array}{c}\text { Produtos } \\
\text { principais }\end{array}$ & $\begin{array}{c}\text { Numero de } \\
\text { empresas } \\
\text { envolvidas }\end{array}$ & $\begin{array}{c}\text { Empresas em } \\
\text { processo de } \\
\text { internaciona- } \\
\text { Lização }\end{array}$ & $\begin{array}{c}\text { Meios da } \\
\text { Internacionalização }\end{array}$ & $\begin{array}{c}\text { Tendência } \\
\text { observada }\end{array}$ \\
\hline Confecções & Vestuário & 91 & 12 & $\begin{array}{c}\text { Exportação por } \\
\text { meio de } \\
\text { representante }\end{array}$ & Crescimento \\
\hline Confecções & Vestuário & 195 & 19 & Representante & Estabilidade \\
\hline $\begin{array}{c}\text { Confecções } \\
\text { de bonés }\end{array}$ & $\begin{array}{c}\text { Bonés e } \\
\text { camisetas }\end{array}$ & 109 & 24 & $\begin{array}{c}\text { Exportação direta e } \\
\text { representante }\end{array}$ & Crescimento \\
\hline Mobiliário & Móveis & 576 & 72 & $\begin{array}{c}\text { Exportação direta e } \\
\text { Representante }\end{array}$ & Crescimento \\
\hline $\begin{array}{c}\text { Metais } \\
\text { Sanitários }\end{array}$ & $\begin{array}{c}\text { Torneiras e } \\
\text { acessórios }\end{array}$ & 34 & 6 & Representante & Crescimento \\
\hline
\end{tabular}

Fonte: dados da pesquisa

Tabela 3: Práticas orientadas para a internacionalização dos clusters

Esses dados, em conjunto, sugerem que o perfil dos participantes influencia de modo significativo nas práticas relacionais entre as organizações e consequentemente naquelas orientadas para a internacionalização. Os diferentes perfis, principalmente os perfis 3 e 4 obtidos desta investigação, podem pautar, segundo Woitchunas e Sausen (2005:9), na relação positiva das práticas existentes de colaboração para a consolidação da rede de cooperação e, obtidas, com base em Verschoore e Balestrin (2006) da disseminação de experiências de ganho de escala, poder de mercado, provisão de soluções, aprendizagem e inovação, redução de custos e riscos e o fator relações sociais.

Conforme foi apontado por Balestro (2004), observa-se que as práticas de governança das redes assumem papel fundamental nas relações entre as empresas. Com destaque para as reuniões de disseminação de experiências de internacionalização culminando com sugestões como as da utilização inicial de agentes de representação para a comercialização em mercados pouco conhecidos. Interferindo na construção de uma rede de confiança de longo prazo.

\section{Conclusão}

Considerando que uma das propostas deste estudo é o de identificar as atividades e os condicionantes endógenos e exógenos para a consolidação dos processos de internacionalização de cinco clusters paranaenses, não foi possível nesta investigação separar os condicionantes exógenos e endógenos pela sua inter-relação e dependência. Observa-se, entretanto, que o perfil dos participantes influencia de modo significativo nas práticas relacionais entre as organizações e consequentemente naquelas orientadas para a internacionalização. Quanto à forma como os condicionantes internos e externos influenciam as empresas, identifica-se que esta é simultânea e correlacionada, o que dificulta o estabelecimento da exata influência de um fator isolado sobre os resultados das ações coletivas. Observa-se que os condicionantes são mais complexos na prática do 
que é apresentado pelas abordagens teóricas e pelos pressupostos da área, permitindo constatar que a relação entre esses fatores se dá de forma recursiva. Constata-se, também, que diferentes contextos e configurações das interações existentes entre as empresas e entidades participantes determinam, a sua forma, os condicionantes e a sua influência específica no processo de internacionalização pretendido. Assim, o fato de a prática relacional existente nos clusters pesquisados ser um fenômeno dinâmico e subjetivo acaba dificultando uma análise direta e relacional com parametrização da pesquisa. Entretanto, os resultados das análises das relações interorganizacionais permitiram identificar alguns subsídios qualitativos para compreensão dos fenômenos estudados e que devem ser consideradas como sugestões de estudos futuros:

- Os clusters são cada vez mais percebidos pela comunidade como fatores contributivos para com o desenvolvimento regional pelo aumento da renda das empresas e das famílias participantes, alterando a sua imagem frente à comunidade e dos próprios empresários. Entretanto, a existência da confiança interpessoal entre os participantes é decisiva para a consolidação das relações sociais ali existentes, e principalmente, para a definição dos seus líderes, da estratégia e dos critérios de governança.

- O perfil cognitivo dos dirigentes das empresas, das entidades governamentais e não governamentais têm papel fundamental na consolidação e na manutenção das relações interorganizacionais e no apoio de estudos e prospecções em mercados desconhecidos e nas orientações técnicas e gerenciais.

- A integração com o apoio governamental local, regional e nacional pode ser visto como diferencial para o acesso aos mercados externos, pois há limitações significativas nas pequenas empresas, ocasionadas pela falta de conhecimento das culturas e demandas dos diferentes mercados externos. Nelas se verifica que a troca de informações é a atividade realizada em conjunto mais importante, o que não implica, no entanto, a percepção de um comportamento social e econômico isomórfico por parte dos empresários garantindo a confiança na troca de informações e na qualidade das informações.

- Para a consolidação da internacionalização é necessário que haja perspectiva de médio e longo prazo e definição e disseminação da estratégia da governança do cluster, pois o imediatismo impede o comprometimento e o investimento orientado para a internacionalização de suas empresas. Considerando que os relacionamentos facilitam o processo colaborativo e de comprometimento com a internacionalização quando ocorrem de forma incremental, ao longo de tempo, e depende da intensidade das relações constituídas. 
- O comprometimento com o processo de internacionalização amplia o relacionamento entre as empresas do cluster permitindo encontrar caminhos, ideias e a obtenção de meios possíveis para mobilizar e aproveitar recursos internos ali existentes, ampliando o uso de formas alternativas de trabalho cooperativo.

- As empresas que estabeleceram alianças sinérgicas com outras empresas no processo de internacionalização tornaram-se mais competitivas, individualmente, com a superação de suas deficiências organizacionais específicas, assim como a valorização da aprendizagem coletiva, a revisão dos processos de relações com o mercado, entre outros.

- A estratégia do cluster, promovido por sua governança, quando amplia a sua ação coletiva propicia às empresas nos seus processos de internacionalização maiores condições de negociação, exposição, confiabilidade e, investimentos orientados para a capacitação técnica e gerencial.

- A reputação dos empresários e dos lideres dos clusters é um fator que influencia significativamente no relacionamento interorganizacional, pois as organizações exercem influência umas sobre as outras, e o fato de compartilharem atividades depende o grau de confiança e do comprometimento.

- Organizações mais centrais, devido à sua posição no inter e na capacidade de gerar iniciativas exercem mais influência sobre as demais empresas do que recebem.

- A existência de estruturas de governança e mecanismos de controle social e técnico que garantam a observância da estratégia estabelecida e dos riscos de oportunismo são prérequisitos essenciais à consolidação das relações.

- As perspectivas dos empresários de reestruturação das empresas e de busca por inovações em processos, recursos e produtos, por meio da cooperação, afetam ampliando os seus relacionamentos enquanto agentes de colaboração e de disseminação das intenções coletivizadas pela governança.

- A subdivisão dos clusters em subgrupos, conforme caracterizado na Tabela 3 e as dificuldades para o estabelecimento dos critérios para se identificar as diferenças entre as empresas e os critérios de participação nos processos colaborativos representam uma barreira para a troca de informações.

- Os mecanismos de comunicação e de troca de experiências e informações entre os participantes. Com cuidados, principalmente por ação da governança, na consideração de que os subgrupos se encontram em níveis de desenvolvimento cooperativo e estágios de governança diferentes. 
- A estratégia de competição se revela como a principal responsável na busca dos condicionantes da competitividade individual das empresas. A estratégia de cooperação se da em busca da realização individual e como promotora de resultados imediatos pela maioria das empresas. Com poucas empresas colaborando na troca de informações estratégicas.

- A distância geográfica ainda se constitui em forte limitador à ampliação das relações interorganizacionais e colaborativas.

- A governança do cluster possui papel significativo como agente de disseminação das relações sociais colaborativas e do conhecimento.

- A divulgação das práticas positivas de internacionalização tanto pela governança como pelas empresas individualmente tem ampliado os grupos e subgrupos colaborativos nesse processo.

Resumidamente, pode-se afirmar que as ações relacionais cooperativas direcionadas à internacionalização são possibilitadas pelo próprio ambiente relacional e as condições internas do cluster construídas historicamente. Os condicionantes endógenos e exógenos modelam os valores individuais dos empresários, de seus colaboradores e das instituições públicas envolvidas em uma relação recíproca e ampliam as perspectivas colaborativas por meio de sua governança quando deixa claro e faz atender, mesmo em parte, as expectativas da internacionalização. Há dados suficientes para se constatar nos clusters pesquisados, que as relações interorganizacionais, quando efetivas, são capazes de disseminar conhecimento entre seus membros transformando o conhecimento tácito existente individualmente em conhecimento explícito para as demais empresas participantes, nas quais há um processo circular de troca de conhecimento que venha a beneficiar a rede como um todo, ocorrendo por meio da busca por novas práticas, valores, comportamentos e sua legitimação no grupo.

Foram observados três dificultadores principais para que esse processo ocorra de maneira mais efetiva - problemas de comunicação, de comportamento isomórfico e a percepção dos riscos da competitividade entre os dirigentes. Em contrapartida, a formalização e a institucionalização dos clusters, bem como a constituição da estrutura de governança, atuam como facilitadores por meio dos canais abertos de socialização e de comunicação. Nesse caso, possuem papel significativo para o estabelecimento da confiança e do comprometimento.

\section{Referências}

Aldrich, H. E. (1979). "Organizations and environments". New Jersey: Prentice-Hall. 
Amato Neto, J. (2000). Redes de cooperação produtiva e clusters regionais: oportunidades para as pequenas e médias empresas. São Paulo: Atlas FundaçãoVanzolini.

Andersson, S. (2000). "The internationalization of the firm from an entrepreneurial perspective". In: International Studies of Management and Organization. v. 30, n. 1, p. 63-92.

Arbix, G.; Salerno, M. S.; De Negri, J. A. (2005). "Inovação via internacionalização, faz bem para as exportações brasileiras". Texto para discussão / IPEA no 1023. Brasília: IPEA. Disponível em: <http://getinternet.ipea.gov.br/biblioteca/> Acesso em: $20 / 03 / 2007$

Argyris, C.; Schön, D. (1982). "Organizational Learning: a Theory of Action Perspective." Reading/Mass: Addison-Wesley.

Auster, E. R. (1994). "Macro and strategic perspectives on inter-organizational linkages: a comparative analysis and review with suggestions for reorientation." In: Shivastava, P.; Huff, A. S.; Dutton, J. E. Advances in strategic management: Interorganizational relations and inter-organizational strategies. Greenwich, Connecticut: Jai Press, p.3-40.

Balbinot, Z.; Marques, R. A.; Rodrigues, F. F. (2007). "Alianças Estratégicas como Condicionantes do Desenvolvimento da Capacidade Tecnológica: O Caso de Cinco Empresas do Setor Eletro-Eletrônico Brasileiro." In: 5th International Conference of the Iberoamerican Academy of Management. 2007, Santo Domingo.

Balestrin, A.; Vargas, L. M. (2004). A dimensão estratégica das redes horizontais de PMES: teorização e evidências. Revista de Administração Contemporânea. Edição Especial,. p. 203-227.

Balestro, M. V. (2004). Características estruturais e mecanismos de governança em redes de cooperação: apontamentos conceituais. In: VERSCHOORE, J. R. S. (Org.). Redes de cooperação: uma nova organização de pequenas e médias empresas no Rio Grande do Sul. Porto Alegre: FEE. p.49-67.

Balestro, M. V.; Mesquita, Z. (2002). "Confiança nas relações inter-organizacionais: aproximando conceitos, ensaiando reflexões." Anais... ENANPAD, Salvador, 22 a 25 de setembro de 2002.

Benito, G.R.G.; Petersen, B.; Welc h, L.S. (2009). "Towards more realistic conceptualizations of foreign operation modes." In: Journal of International Business Studies. V. 40, n. 9, December, p. 1455-70. 
Brown, J. S., Duguid, P. (1991). "Organizational Learning and communities-of-practice: Toward a unified view of working, learn., and innovation." Organization Science. 2 (1), 40-57.

Cândido, G.A.; Abreu, A.F. (2004). "Fatores críticos de sucesso no processo de formação, desenvolvimento e viabilização de redes organizacionais: um estudo exploratório. In: XXVIII Encontro Anual da ANPAD. Anais... Curitiba: ANPAD, CD ROM.

Carlson, S. (1975). "How foreign is foreign trade: a problem in international business research." Uppsala: Uppsala University Press.

Carrão, A. M. R. (2004). Cooperação entre empresas de pequeno porte em pólos industriais: um estudo comparativo. Revista de Administração da Universidade de São Paulo. São Paulo: USP, v. 39, n. 2, p.186-195, abr./maio/jun.2004.

Casarotto Filho, N. (2005). "Instrumentos de integração e governança em aglomerações competitivas." Disponível em http://www.ucdb.br/coloquio/arquivos/Casarotto.pdf Acesso em 30/04/2010.

Casarotto Filho, N.; Pires, L. H.(2001). Redes de pequenas e médias empresas e desenvolvimento local: estratégias para a conquista da competitividade global com base na experiência italiana. 2. ed. São Paulo: Atlas.

Cassiolato, J. E.; Lastres, H. M. M. (2003). "O foco em arranjos produtivos e inovativos locais de micro e pequenas empresas." In: LASTRES, H. M. M.; CASSIOLATO, J. E.; MACIEL, M. L. (Org). Pequena empresa: cooperação e desenvolvimento local. RJ: Relume Dumará.

Castells, M. (2006). A sociedade em rede. Tradução de Roneide Venâncio Majer. 9. ed., v. 1. São Paulo: Paz e Terra.

Castro, Marcos De. (2007). Relacionamentos interorganizacionais e resultados: estudo na associação dos comerciantes de materiais de construção da região de Guarapuava -PR." Curitiba, 2007. 171 p. Dissertação (Mestrado) - Universidade Federal do Paraná, 2007.

Cavusgil, S. T. (1980). "On the internationalization process of firms." European Research. Child, J.; Faulkner, D. (2009). "Strategies of cooperation: managing alliances, networks." joint em 23/08/2009.

Child, J.; Rodrigues, S. B. (2006). "The role of trust in international entrepreneurship." In: Encontro dos Programas de Pós-Graduação em Administração, 2006, Salvador. Anais ENANPAD, 
Colla, J. E. (2009). "A Influência da Estratégia Colaborativa no Conteúdo Estratégico em Rede de Empresas." Dissertação de mestrado. PPGADM da Universidade Federal do Paraná.

Cunha, S. K. ; Cunha, J. C.(2005). Competitividade e Sustentabilidade de um Cluster de Turismo: uma proposta de modelo sistêmico de medida de impacto do turismo no desenvolvimento local. Revista de administração contemporânea, Rio de Janeiro, v. 9, n. $2^{a}$ edição especial, p. 101-124.

Cunha, S. K. e Cunha, J. C. (2005). "Tourism Cluster Competitiveness and Sustaintability: Proposal for a Systemic Modell to Measure the Impact of Tourism on Local Development." In: BAR. Brazilian Administration Review, Brasil, v. 2, n. N.2, p. 4762.

Cunha, S. K; Cunha, J. C. (2006). Clusters de turismo: abordagem teórica e avaliação. Revista de Desenvolvimento Econômico. Salvador: UNIFACS, v. 8, n. 13, p.60-67, jan. 2006.

Cunha, S. K.; Cunha, J. C. (2007). "Experiências Paranaense na avaliação Sistêmica de Clusters." In: Fauré, Yves-A; Hasenclever, L.. (Org.). Caleidoscópio do Desenvolvimento Local no Brasil: diversidade das abordagens e experiências. 1 ed. Rio de Janeiro: IEUFPRJ., 2007, v. 1, p. 93-130.

Czajkowski, A. (2009). Redes de Cooperação E Desenvolvimento do Turismo Local: Um Estudo de Caso no Circuito Italiano de Turismo Rural - Município de Colombo-Pr. Dissertação de Mestrado. PPDA- UP. 2009.

Czajkowski, A.; Cunha, S. K. (2010). "Aglomeração e Coordenação da Rede de Cooperação em Aglomerado de Turismo." In: Turismo. Visão e Ação (Itajaí), v. 12, p. 92113.

Eusebio, R.; Rialp, A. (2002). "Innovación tecnológica y resultado exportador: un análisis empírico aplicado al sector textil-confección español." Document de treball, no 4, Universitat Autònoma de Barcelona, Facultat de Ciències Econòmiques i Empresarials, Departament d'Economia de l'Empresa.

Facco, C. A. e Cunha, S. K. (2009). "Internacionalização, Aprendizagem e Acumulação de Capacidades Tecnológicas: O Caso da Cristófoli Biossegurança". In: III Seminário LatinoIberoamericano de Gestión Tecnologica, 2009, Cartagena - Bogotá. Anais do XIII Seminário Latino-Iberoamericano de Gestión Tecnologica. CARTEGENA : ALTEC 2009, . v. 1. p. 1-16. 
Filipescu, D. A. (2007). "Innovation and internationalization: a focus on Spanish exporting firms." 65p. Treball de recerca - Universitat Autònoma de Barcelona, Facultat de Ciències Econòmiques i Empresarials, Departament d'Economia de l'Empresa.

Furtado, J. (2004). "Quatro eixos para a política industrial." In: FLEURY, M.T.L., FLEURY, A Política Industrial. V. 1. São Paulo: FEA/ USP, Biblioteca Valor Publifolha, p. 47-78.

Gerolamo, M. C. (2007). Gestão de desempenho em clusters e redes regionais de cooperação de pequenas e médias empresas: estudos de casos brasileiros e alemães e proposta de um modelo de análise. 2007. 227 f. Tese (Doutorado em Engenharia de Produção) Escola de Engenharia de São Carlos - Universidade de São Paulo.

Gonzalez, R.e Cunha, S. K. (2010). Trajetória de internacionalização e Capacidade tecnológica da cia. Iguaçu de Café solúvel. In: Anais Simpósio de Gestão de Inovação Tecnológica 2010. Nitérói.

Grandori, A.; Soda, G. (1995). "Inter-firm networks: antecedents, mechanisms and forms." Organization Studies, v. 16, n.2, p. 183-214.

Gulati, R.; Gargiulo, M. (1999). "There do interorganizational network come from?" The American Journal of Sociology, v. 104, n.5, p.1439-1493, March.

Hall, R. H. (2004). "Organizações: estruturas, processos e resultados." São Paulo: P. Hall.

Human, S. E.; Provan, K. G. (1997). "An emergent theory of structure and outcomes in small firm strategic manufacturing networks." Academy of Management Journal, v. 40, n. 2, p. 368-403.

Ipardes. (2006). "Identificação, caracterização, construção de tipologia e apoio na formulação de políticas para os arranjos produtivos locais (APLs) do Estado do Paraná: diretrizes para políticas de apoio aos arranjos produtivos locais (APLs)." Curitiba: IPARDES.

Johanson, J.; Vahlne, J. (2009). "The Uppsala Internationalization process model revisited: from liability of foreignness to liability of outsidership." Journal of International Business Studies, V. 40, n. 9, p. 1411-31.

Judice, V.M.M. (2006). "Competências em Internacionalização e Inovação em Biotecnologia no Brasil." Journal of Technology Management \& Innovation, v.1, Issue 4, p. 95-107.

Larsson, R.; Bengtsson, L.; Henriksson, K.; Sparks, J. (1998). "The Interorganizational Learning Dilemma: Colective Knoledge Development in Strategic Alliances." Organization Science, v.9, no 3, May-June, p. 285-305. 
Lastres, H. M. M.; Cassiolato, J. E. (2009). Glossário de arranjos e sistemas produtivos e inovativos locais: quinta revisão. Rede de Pesquisa em Sistemas Produtivos e Inovativos Locais. [S.I.: s.n.], p.1-30. jun.2005. Disponível em: <http://www.redesist.ie.ufrj.br/> Acesso em 13 jan.2009.

Lima, F.G.S.N.; Campos Filho, L.A.N. (2009). "Mapeamento dos Estudos Contemporâneos em Alianças e Redes Estratégicas." Revista Brasileira de Gestão e Negócios. V. 11, no 31.

López, J.; García, R. M. (2004). "Capacidad tecnológica y comportamiento exportador: una aproximación desde la teoría de recursos y capacidades." In: XIV Congreso ACEDE Asociación Científica de Economía y Dirección de Empresa, Murcia.

Maskell, P.; Bathelt, H.; Malmberg, A. (2005). "Building Global Knowledge Pipelines: The Role of Temporary Clusters." DRUID Working Paper 2005. Copenhagen. Web Site: http://www.druid.dk/wp/wp.html. Acesso em 13/08/2009.

Mcnamara, D. (2005). "Learning Communities and Global SMEs." APEC ASC Conference 2005. Korea.

Mendonça, A. T. B. B. E Cunha S. K. (2011). Acumulação de capacidade tecnológica em empresas internacionalizadas e não internacionalizadas de um sistema setorial de inovação. In: Revista Espacios, Espacios. Vol. 32 (3) Caracas Venezuela.

Olivares, J.E.L. (2003). "Estructura organizacional en red (EOR): explorando suas bases teóricas." In: XXVII Encontro da ANPAD. Anais... Atibaia: CD ROM.

Oliver, C. (1990). "Determinants of interorganizational relationship: integration and future directions." Academy of Management Review, v.15, n.2, p. 241-265, April.

Paiva, F. E Barbosa, F. (2001). "Redes Organizacionais no Sistema de Cluster: reflexões sobre sua posição estratégica na busca de oportunidades pelas pequenas e médias empresas." In: Encontro Anual da ANPAD, Campinas-SP, 2001. Anais... Campinas: ANPAD.

Pfeffer, J.; Salancik, G. R. (1978). "The external control of organizations: a resource dependence perspective." Nova York: Harper and Row.

Rezende, S.F.L.; Versiani, A.F. (2007). "Relacionamentos inter-subsidiárias e processos de internacionalização de multinacionais." Revista de Administração - RAUSP, v. 42, n². São Paulo, abril/junho.

Root, Franklin. (1998). "Entry strategies for international markets." MA: Lexinton Books. 
Scherer, F. O.; Zawislak, P. A. (2007). Trajetória de crescimento em rede de cooperação: limites - inovação - desenvolvimento. In: Encontro da Anpad, 31, 2007, Rio de Janeiro. Anais... Rio de Janeiro: [s.n.], p.1-16.

Schermerhorn Jr. (1975). "Determinants of interorganizational cooperation." Academy of Management Journal, v. 18, n.4, p. 846-856.

Sebrae. (2007). "Relatório: Pequenas e médias empresas na reestruturação industrial."

Tálamo, J. R. (2008). Formação e gestão de redes de cooperação empresarial. 233f. Tese (Doutorado em Engenharia de Produção) - Setor de Ciências Exatas, Escola Politécnica da Universidade de São Paulo, São Paulo.

Tallman, S.; Jenkins, M. Henry, N. Pinch, S. (2004). "Knowledge Clusters and Competitive Advantage." Academy of Management Review, v. 29, n.2, p. 258-271.

Thomaz, J.C.; Brito, E.P.Z.; Marcondes, R.C.; Ferreira, F.C.M. (2009). "Sustentabillidade e Crescimento do Arranjo Produtivo de Semijoias de Limeira." IV Encontro de Estudos em Estratégia - 3Es. Recife.

UNIDO. (2001). "Development of cluster and networks of SME's." The UNIDO Programme. United Nations Industrial Development Organization: Viena.

Verschoore Filho, J. R. de S.(2008). O programa redes de cooperação: uma análise os instrumentos de administração pública para o desenvolvimento sócio-econômico. In: Congreso Internacional del CLAD sobre la Reforma del Estado y de la Administración Pública, 8, 2003, Panamá. Anais Eletrônicos... Panamá: [s.n.]. Disponível em: <http://unpan1.un.org/intradoc/groups/public/documents/CLAD/clad0047518.pdf>. Acesso em: 21 jun. 2008.

Verschoore, Filho, J.R.S. ; Balestrin, A. (2006). Fatores competitivos das empresas em redes de cooperação.In: Encontro da Anpad, 30, 2006, Salvador. Anais... Bahia: [s.n.] p.1-16.

Vigotsky, L.S. (1978). "A Formação social da mente." São Paulo: Universidade de São Paulo.

Welch, L.; Luostarinen, R. (1998). I"nternationalization: evolution of a concept." Journal of General Management, v. 14, n. 2, p. 36-64.

Wenger, E.C.; Snyder, W. M. (2001). "Comunidades de Prática: a fronteira organizacional." In: Aprendizagem Organizacional. Harvard Business Review: Editora Campos, p. 9-26.

Woitchunas, L. F.; Sausen, J. O. (2005). Fatores críticos de sucesso no processo de formação, desenvolvimento e manutenção de Redes de cooperação e suas relações com 
o desenvolvimento local e regional. In: Encontro da Anpad, 29, Brasília. Anais... Distrito Federal: [s.n.]. p.1-16.

Yin, R. K. (2001). "Estudo de caso: planejamento e métodos." 2 ed. Porto Alegre: Bookman, 2001.

Zollo, M.; Reuer; J. Singh, H. (2002). "Interorganizational Routines and Performance in Strategic Alliances." Organization Science, v. 13, n. 6, Nov/Dec, p. 701-713. 